\title{
Generation Technique of Hypersonic Liquid Jets Using a Single-Stage Powder Gun and It's Application
}

\author{
○学 坂倉 徹 (名工大院) 正 施 紅輝（名工大） \\ 正 伊藤 基之 (名工大)
}

Toru SAKAKURA, Nagoya Insti tute of Technology, Gokiso-cho, Showa-ku, Nagoya 466, Japan Hong-Hui SHI, Nagoya Institute of Technology, Gokiso-cho, Showa-ku, Nagoya 466, Japan Motoyuki ITOH, Nagoya Institute of Technology, Gokiso-cho, Showa-ku, Nagoya 466, Japan

Key Words : Hypersonic Liquid Jets, Single-Stage Powder Gun

\section{1. 緒言}

高速液体噴流の生成装置は多様な分野での応用が考えら れる。例えば、固体面への液体の高速衝突現象の解明など には欠かすことができない。この現象は、雨滴の航空機へ の衝突や水滴による大型蒸気タービン翼表面の損傷などで 問題となる。一方、ウォータージェット加工などでは、液 体の高速衝突が積極的に利用され、材料の切断・加工技術 として使われている。そこで本研究では、高速噴流の中で も数千 $\mathrm{m} / \mathrm{s}$ の噴流速度を得ることが可能なパルス噴流に着目 し、その生成の方法あるい噴流構造を調べた。生成装置と しては、単段式火薬銃を用いて飛翔体を高速発射し、ズ ル内の静止液体に衝突させ、約 $3 \mathrm{~km} / \mathrm{s}$ の高速液体噴流を生成 する。そして、飛翔体あるいはノズル形状が噴流生成に与 える影響を調べると共に、ノズル内の流れについてTVD差分 法を用いて数值解析を行った。

\section{2. 実験装置および実験方法}

実験装置の概略図をFig.1に示す。装置は火薬銃本体、飛 行管、観測部およびストッパで構成され、装置の全長は約 $3.5 \mathrm{~m}$ である。火薬銃本体は容積 $37.5 \mathrm{~mm}^{3}$ の火楽室および内 径15 mm、長さ $1.1 \mathrm{~m}$ の加速管で構成される。実験時には空 気抵抗による飛翔体速度の低下防止之飛行の安定性を考文、 加速管内および飛行管内は真空状態にした。また、噴流が生 成される観測部内は大気圧とした。推進薬にはシングル ベースの無煙火薬 (NY500、日本油脂製)を用い、装薬量は 6〜12 $\mathrm{g}$ の間で変えて実験を行った。飛翔体は超高密度ポリ エチレン製であり、直径 $15.15 \mathrm{~mm}$ 、長さ20,30, $40 \mathrm{~mm}$ の3種 類を用いた。噴流生成部はステンレス製のノズル、シリン ダ、スペーサーリングおよびそれらを固定するアウターシ リンダで構成 (Fig.2)され、飛行管と観測部の間のフランジ に固定した。また、シリンダの前後をマイラー膜で仕切

り、その内部に液体 (約 $8 \mathrm{cc}$ )を満たした。実験で使用したノ ズルおよびシリンダの形状をFig.3に示す。

第一段階として装薬量と飛翔体速度、飛翔体速度と噴流 速度の関係を明らかにするため、同一のノズル、シリンダ を用い装薬量および飛翔体を変えて実験を行い、飛翔体おう よび噴流の速度を測定した。次にノズル形状のみを変えて 同様の実験を行った。また、噴流となる液体の粘性が噴流 生成および噴流形状に与える影響を調べるため、濃度の異 なるグリセリン水溶液を用いて実験を行った。さらに、ノ ズル出口から $100 \mathrm{~mm}$ 前方に厚さ $4 \mathrm{~mm}$ 真鍮板を固定し、噴 流との衝突実験を行った。

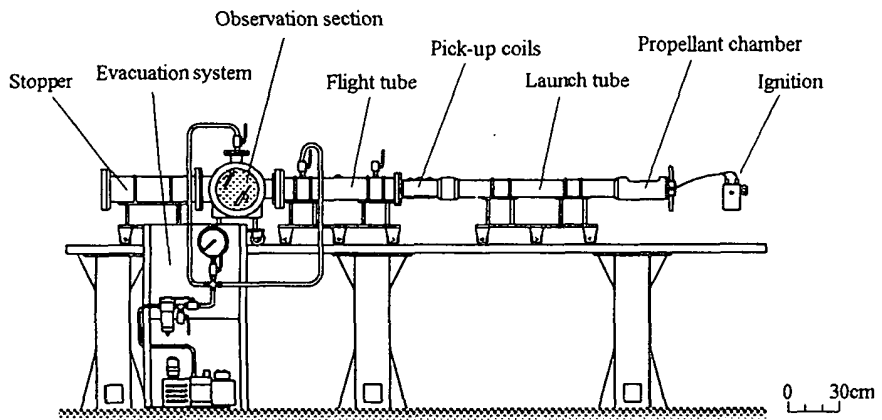

Fig.1 Schematic of experimental apparatus
次に、噴流形状と喷流速度を知るために高速度カメラ（弨 高速デジタルフレーミング/ストリークカメラ IMACON 468)により一定の時間間隔で6枚の映像を撮影した。1コマ

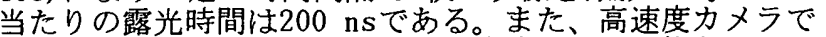
は噴流の影写真が得られるため、噴流の表面状態を見るこ とができない。そこで、噴流を一眼レフカメラにて瞬間写 真撮影を行った。撮影時には暗室内に観測部およびシャッ ターが開放状態にされたカメラを設置し、噴流発生時にナ ノパルスライト(菅原研究所製 発光時間 $180 \mathrm{~ns}$ )を発光さ せ撮影した。

\section{3. 数值計算}

圧縮性流体の超音速流れは衝軗波を伴うので、圧力・密 度の不連続面が発生する。そこで、数值解の空間的な変動 量の total variationが時間進行に伴って增幅しないように理 論的に許容できる制限を設け、有限な格子数で衝撃波のよ うな不連続面が捕獲できるTVD法を用いる。本解析で用い た粘性を考慮に入れた非定常軸対称流れの無次元化支配方 程式を以下に示す。

$$
\begin{aligned}
& \frac{\partial \mathrm{Q}}{\partial \mathrm{t}}+\frac{\partial \mathrm{F}_{1}}{\partial \mathrm{x}}+\frac{\partial \mathrm{F}_{2}}{\partial \mathrm{r}}+\frac{\partial \mathrm{G}_{1}}{\partial \mathrm{x}}+\frac{\partial \mathrm{G}_{2}}{\partial \mathrm{r}}+\frac{\mathrm{H}}{\mathrm{r}}=0 \\
& \mathrm{Q}=\left[\begin{array}{c}
\rho \\
\rho \mathrm{u} \\
\rho \mathrm{v}
\end{array}\right], \mathrm{F}_{1}=\left[\begin{array}{c}
\rho \mathrm{u} \\
\rho \mathrm{u}^{2}+\mathrm{p} \\
\rho \mathrm{uv}
\end{array}\right], \mathrm{F}_{2}=\left[\begin{array}{c}
\rho \mathrm{v} \\
\rho \mathrm{uv} \\
\rho \mathrm{v}^{2}+\mathrm{p}
\end{array}\right], \\
& \mathrm{G}_{1}=\frac{1}{\mathrm{Re}_{\mathrm{r}}}\left[\begin{array}{c}
0 \\
\mathrm{fr} \\
-\tau
\end{array}\right], \mathrm{G}_{2}=\frac{1}{\operatorname{Re}_{\mathrm{r}}}\left[\begin{array}{c}
0 \\
-\tau \\
\mathrm{fr}
\end{array}\right], \mathrm{H}=\frac{1}{\mathrm{r}}\left[\begin{array}{c}
\rho \mathrm{v} \\
\rho \mathrm{uv}-\tau / \operatorname{Re}_{\mathrm{r}} \\
\rho \mathrm{v}^{2}-\alpha / \mathrm{Re}_{\mathrm{r}}
\end{array}\right]
\end{aligned}
$$

ここで、 $\mathrm{x} 、 \mathrm{r}$ は軸方向、半径方向を表し、 $\mathrm{u} 、 \mathrm{v} 、 \rho 、 \mathrm{p}$ はそ れぞれ $\mathrm{x}$ 方向の速度、 $\mathrm{r}$ 方向の速度、液体の密度、圧力を表 す。なお、液体の状態方程式には次のTait式を(2) 用いる。

$$
\mathrm{p}+\mathrm{B}=\left(\rho / \rho_{0}\right)^{\mathrm{n}}\left(\mathrm{p}_{0}+\mathrm{B}\right)
$$

但し、 $\mathrm{B}=\mathrm{C}^{2} \rho \alpha \mathrm{n} 、 \mathrm{p} 0=1013 \mathrm{kPa} 、 \rho \sigma=1000 \mathrm{~kg} / \mathrm{m}^{3} 、 \mathrm{C}_{0}=1428 \mathrm{~m} / \mathrm{s}, \mathrm{n}=$ 7.415である。

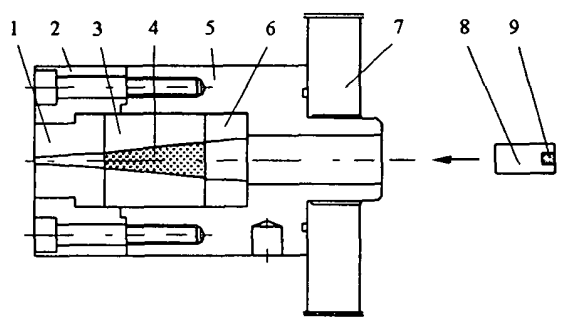

1: Nozzle 2: Outer cylinder 3: Inner cylinder 4: Liquid 5:Support 6: Spacer ring 7: Flange 8: Projectile 9: Magnet

Fig. 2 Schematic of jet generating part

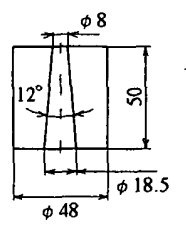

(a) Cylinder

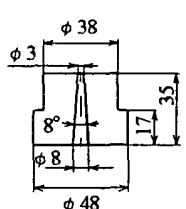

(b) Nozzle-1

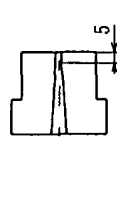

(c) Nozzle-2

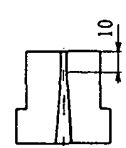

(d) Nozzle-3

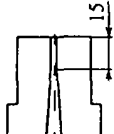

(e) Nozle-4
Fig. 3 Schematic of cylinder and nozzles 


\section{4. 実験結果および考察}

4.1 装薬量による飛翔体および噴流速度の変化

Fig. 4に装薬量による飛翔体速度の変化を示す。図中の実 線は、内部弾道学(1)による理論值を示す。実験結果は、理 論值に対し全体的に下回った值をとっている。これは理論 では飛翔体の加速過程において飛翔体と加速管内壁との摩 擦が考慮されていないためと考えられる。また、飛翔体の 質量の違いは、それほど飛翔体速度には影響を及ぼさない といえる。飛翔体と噴流の速度の関係を数值計算結果と合 わせてFi.g. 5に示す。実験値は大きくばらつき、定性的にも 理論値と一致していない。ここで、噴流生成の機構を考え てみると、衝突の際飛翔体と静止液面との接触面から発生 する圧縮波が、シリンダーおよびノズル内で反射、干渉 し、液柱の内部圧力を高める。この圧力により液柱先端は 著しく加速され、高速噴流としてノズル孔から噴出する。 よって、飛翔体の液柱への進入状態は噴流生成に大きな影 響を与えると考えられる。実験後の飛翔体を観察すると、 その変形の様子が個々に異なっていた。このことから、飛 翔体の液柱内への進入と共に起こる変形が、同条件での実 験においても異なり、それが液中内での圧縮波の挙動に影 響を及ぼしたと考えられる。なお、本実験で使用した装置 の性能を評価するための主パラメーターである飛翔体速度 に対する噴流速度の比は、1.0〜3.1であった。

\section{2 ノズル形状が噴流速度に与える影響}

ノズル出口に直線部分をそれぞれ $5,10,15 \mathrm{~mm}$ 設けたノズ ルを使用し、隫流速度に与える影響を調べた。結果をFig. 6 に 示す。同図より、同じ装䓠量に対して、適切な直線部分を 設けることでより効率よく噴流速度を高めることができる ことがわかる。また、直線部分を作ることでノズル孔付近 の強度が上がり、ノズル孔が広がるなどの変形が抑制できる。

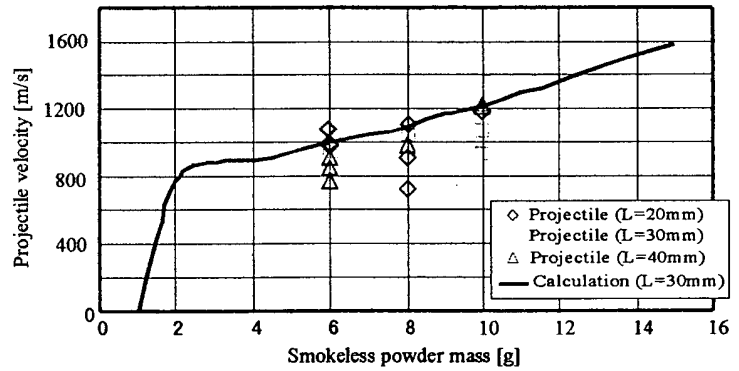

Fig.4 Variation of projectile velocity with smokeless powder mass

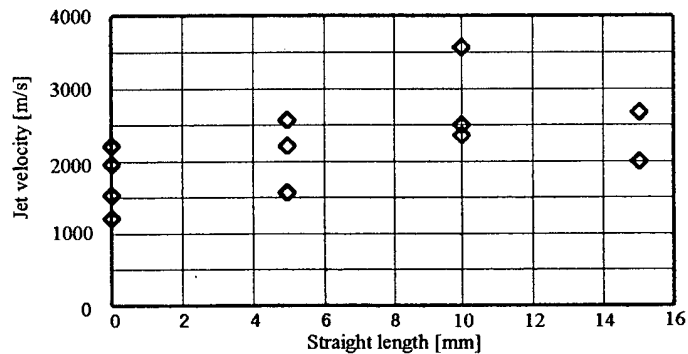

Fig. 6 Variation of jet velocity with straight length of nozzle Powder mass : $10 \mathrm{~g}$ Projectile : $\mathrm{L}=30 \mathrm{~mm}$

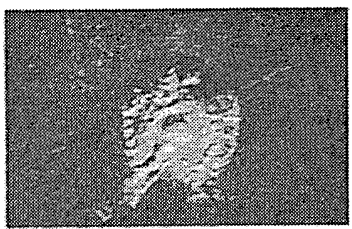

(a) Distilled water

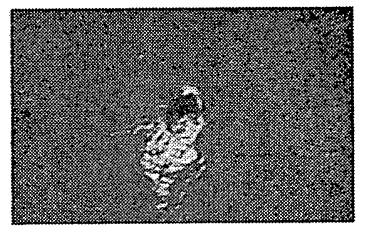

(b) $80 \%$

\section{3 液体の粘性が噴流に与える影響}

グリセリンの体皘濃度がそれぞれ95,90,80\%の3 種類のグ リセリン水溶液を用いて実験を行った。之れぞれの粘度は 室温 $\left(23^{\circ} \mathrm{C}\right)$ において、762,236,78 cPであつた。液体の粘度 と噴流速度の関係をFig. 7に示す。噴流となる液体に蒸留水 を用いるより、蒸留水にグリセリンを混合させ適度に粘度 を高くした液体を用いたときの方が、噴流速度が高くなつ ているのが分かる。また、液体の持つ粘度が高いほど噴出 後における分裂が少なく、そのため噴流形状はより棒状に 近いと考えられる。すなわち、噴流が持つエネルギーの搪 散が少ないと考えられる。これは、Fig. 8に示寸真鍮板の損 傷跡からも分かるように粘度が高いときには厚さ $4 \mathrm{~mm}$ 真 鍮板を貫通していることからも伺い知ることができる。

4.4 噴流の形状

Fig.9に高速度カメラにより捉えた噴流の連続写真を示す。 生成された噴流は、ノズル噴出直後から噴流先端の急膨張に よるキャビテーションや空気抵抗の影響により、微粒化の進 行が激しく進行し、半径方向に大きく広がっている様子が分 かる。さらに噴流先端においては、指状に分裂している。

5. 結言

1) 本実験で使用した装置の性能を評価するための主パラ メーターである飛翔体速度に対する噴流速度の比は、最大 で3.1を得た。

2) ノズル形状として、ノズル出口に適切な直線部分を設け ると、より効率よく噴流速度を高めることができる。

3）噴流に用いる液体の粘度を適度に高くすることによって 噴流速度を高めることができると共に、噴流の分裂あるい は拡散をも抑制することができる。

\section{参考文献}

(1) 工業火薬協会編，工業火薬ハンドブック,共立出版，(1966) 435-448

(2) 能見基彦 ほか 3 名,機論, 57-535, B (1991), 914-921

(3) 高山和喜編, 衝撃波ハンドブック,シュプリンガーフェ ラーク東京, (1995), 515

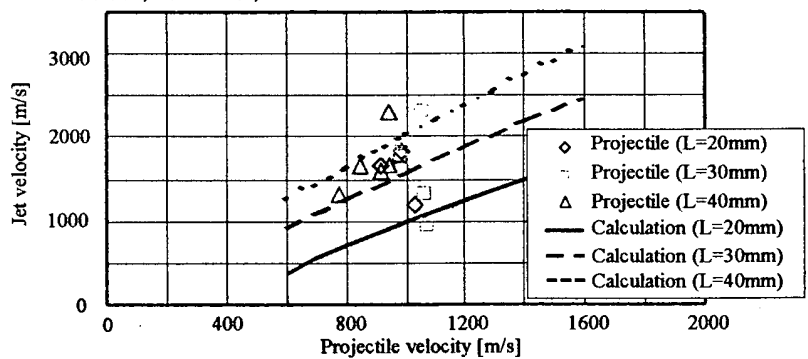

Fig. 5 Variation of jet velocity with projectile velocity

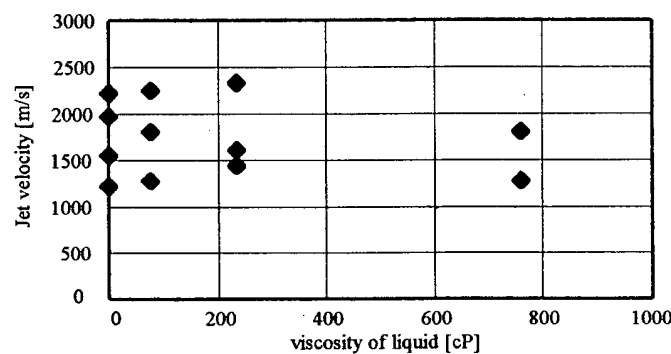

Fig. 7 Variation of jet velocity with viscosity of liquid jet Powder mass : $10 \mathrm{~g}$ Projectile : $\mathrm{L}=30 \mathrm{~mm}$ Nozzle : 1

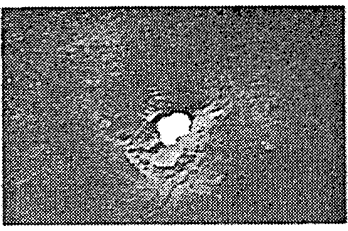

(b) $90 \%$

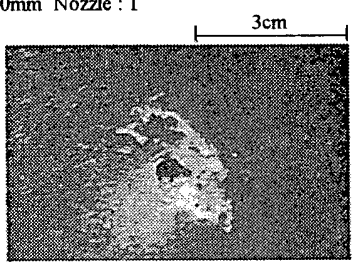

(b) $95 \%$

Fig.8 Damage of $4 \mathrm{~mm}$ thick brass plate caused by the impact of liquid jet
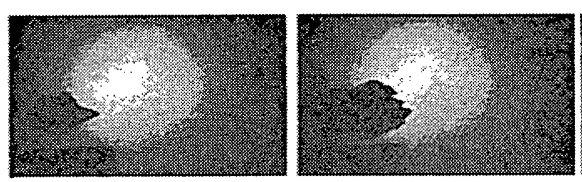

$611 \mathrm{~m} / \mathrm{s}$

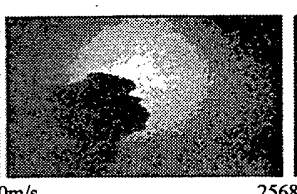

$2370 \mathrm{~m} / \mathrm{s}$
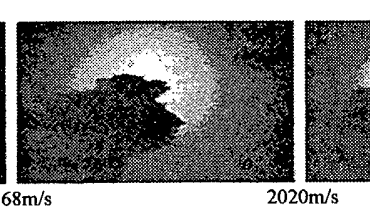

$10 \mathrm{~cm}$

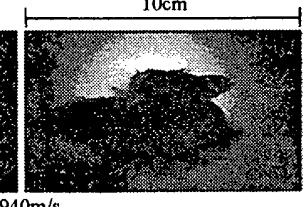

Fig.9 Photographs of water jet 